\title{
Intermodal network expansion in a competitive environment with uncertain demands
}

\author{
Fateme Fotuhi and Nathan Huynh*
}

Department of Civil \& Environmental Engineering, University of South Carolina, Columbia, SC USA

\section{H R O N I C L E}

Article history:

Received September 172014

Received in Revised Format

October 92014

Accepted October 172014

Available online

October 172014

Keywords:

Intermodal terminal location

Competition

Robust optimization

Simulated annealing

\begin{abstract}
A B S T R A C T
This paper formulates robust optimization models for the problem of finding near-optimal locations for new intermodal terminals and their capacities for a railroad company, which operates an intermodal network in a competitive environment with uncertain demands. To solve the robust models, a Simulated Annealing (SA) algorithm is developed. Experimental results indicate that the SA solutions (i.e. objective function values) were comparable to those obtained using GAMS, but the SA algorithm could obtain solutions faster and could solve much larger problems. In addition, the results verify that solutions obtained from the robust models were more effective in dealing with uncertain demand scenarios.
\end{abstract}

\section{Introduction}

Intermodal freight transport is the movement of goods in one and the same loading unit or road vehicle, which uses successively two or more modes of transport without handling the goods themselves in changing modes (United Nations, 2001). This research deals with the locations of rail-highway intermodal terminals where the modal shift occurs. A significant portion of the total cost and time in intermodal services is attributed to the drayage movements and intermodal terminal operations. Thus, the location of an intermodal terminal plays an important role in improving efficiency and attractiveness of intermodal services (Sorensen et al., 2012).

Most of the intermodal terminal location studies in the literature solve for the optimal locations without considering existing terminals in the network. This assumption is not realistic in practice as pointed out by Gelareh et al. (2010). In today's competitive environment, railroad companies are constantly looking to expand their intermodal networks to meet customers' demands and to increase market share. This is often accomplished by incrementally adding a few new terminals at a time. Solving the location problem that takes into account a company's existing terminals as well as those of competitors is more challenging. This study seeks to fill this gap in existing literature by developing a mathematical model that addresses competition in intermodal terminal location decisions. Competition involves new incoming terminals competing against existing terminals in the network for market share.

* Corresponding author. Tel: +1-803-777-8947

E-mail: huynhn@,cec.sc.edu (N. Huynh)

(C) 2014 Growing Science Ltd. All rights reserved.

doi: $10.5267 / j$.jijiec.2014.10.002 
There are a few additional challenges involved in developing the proposed model. The first is uncertainty in demand. Demand for an intermodal terminal is the result of the commodity flow originated or terminated in the region where the terminal is located (Chiranjivi, 2008). Accurate longrange prediction of commodity flow is difficult because of uncertainty in economic situations and changes in supply chain decisions, infrastructure, and regulations. For example, most freight-related forecasts failed to predict the global recession that started in 2009. Thus, it is crucial for a strategic model to explicitly account for uncertainty in demand. The second challenge is determining the appropriate throughput capacity for the new terminal to avoid the situation of under-equipping the terminal which would lead to delays at the terminal (Nocera, 2009) or over-equipping the terminal which would lead to underutilized staff and resources. Throughput capacity is the total number of containers that can be processed by a terminal in a year and is usually expressed in TEUs (Twenty-foot Equivalent Units) (Bassan, 2007).

The objective of this work is to develop a mathematical optimization model which addresses all of the challenges and issues mentioned above. Specifically, the model seeks to determine the locations for the new intermodal terminals and their throughput capacities while considering competition and uncertainty in freight demands. The developed model contributes to the existing body of work on intermodal terminal location by explicitly incorporating competition and uncertainty in freight demand in the formulation. The proposed model is applicable for intermodal networks where private rail carriers are responsible for their own maintenance and improvement projects; the U.S. intermodal networks operate under this model.

The rest of the paper is organized as follows. Section 2 provides a summary of related studies; three topics are addressed: (1) rail-highway intermodal terminal location problem, (2) terminal throughput capacity, and (3) competitive location. Section 2 also provides a brief review of the robust optimization concept. Section 3 presents the developed mathematical model. Section 4 discusses the developed simulated annealing algorithm. Section 5 discusses the results from numerical experiments and the case studies. Section 6 discusses the practice implications of various managerial decisions. Lastly, Section 7 provides concluding remarks and directions for future work.

\section{Literature review and background}

\subsection{Literature review}

\subsubsection{Rail-highway intermodal terminal location problem}

Studies of terminal locations are performed at strategic planning level (Crainic, 1998) which involves different stakeholders with different objectives (Sirikijpanichkul \& Ferreira, 2005). Over the years, the hub-based network structure has emerged as the preferred method for moving intermodal shipments (Ishfaq \& Sox, 2011). A hub is a location where flow are aggregated/disaggregated, collected and redistributed (Arnold, Dominique \& Isabelle, 2004). Similar to hubs, intermodal terminals are the transfer points at which containers are sorted and transferred between different modes (Meng \& Wang, 2011). The emergence of hub based intermodal networks indicates that economies of scale are the principle force behind their preferred design (Slack, 1990). Also, because intermodal networks are combinations of their respective modal networks, it is natural that the hub network has emerged as the most suitable network design for intermodal logistics (Bookbinder \& Fox, 1998).

In an intermodal hub network, smaller shipments are gathered and consolidated at distribution centers. At the next step, all consolidated containers are collected from these distribution centers and shipped to the terminals via drayage and then between a set of transfer terminals (i.e. rail-highway intermodal terminals). Finally, trucks transport loaded containers to their final destinations (Ishfaq \& Sox, 2011). 
Rutten (1995) was the first to find terminal locations which will attract enough freight volume to schedule daily trains to and from the terminal. Arnold et al. (2004) developed a rail-highway intermodal terminal location problem with each mode as a sub-graph and considered transfer links to connect these sub-graphs to each other. Racunica and Wynter (2005) developed a model to find terminals in a rail-highway intermodal network. They considered a nonlinear concave-cost function to find these optimal hubs. Groothedde et al. (2005) developed a hub-based network for the consumer goods market. They compared the single highway mode with a highway-water intermodal. They showed that the intermodal approach is more effective than the unimodal approach (with just highway). Limbourg and Jourquin (2009) proposed a model to find hub locations in a rail-highway intermodal network. They developed a heuristic to find hub locations for a road network and found rail links which passes through these hubs. Meng and Wang (2011) proposed a mathematical program for a huband-spoke intermodal network. The main difference between their model and earlier works is that it considered more than one pair of hubs for moving containers from an origin to a destination. Their work considered a chain of terminals to move shipments with different types of containers.

Mode choice has been incorporated into the hub location models. Ishfaq and Sox (2010) developed an integrated model for an intermodal network dealing with air, highway and rail modes. Their model allowed for direct shipment between origin and destination pairs using highway. It found the optimal locations for intermodal terminals and distribution of shipments among pairs of intermodal terminals by minimizing the total transportation cost, transfer cost at the terminal and fixed cost of opening a hub. In their later work, they proposed a rail-highway hub intermodal location-allocation problem (Ishfaq \& Sox, 2011). Their model found the optimal location of hubs as well as optimal allocation of shipments for an Origin-Destination (OD) pair to selected hubs. Their model considered the fixed cost of opening a terminal, transportation cost, and the cost of delay at terminals. Sorensen et al. (2012) modeled a hub-based rail-highway intermodal network with the option of direct shipment. Different fraction of shipments for an OD pair can use highway only or a combination of highway and rail (i.e. intermodal). Fotuhi and Huynh (2013) proposed a model, which jointly selected terminal location, shipping modes and optimal routes for shipping different types of commodities. Their model allowed decision makers to evaluate scenarios with more than two modes.

\subsubsection{Terminal throughput capacity}

The traditional capacitated facility location problem in which facilities have limited capacities has been studied extensively. Drezner (1995) provided a survey of facility location studies with limited capacity. Some researchers have investigated the location planning problems with variable capacities. Verter and Dincer (1995) were the first to integrate location decision and variable capacity planning for a new facility. They developed a model to minimize the fixed cost of opening a new facility, variable cost for capacity acquisition, and total transportation cost. In the transportation domain, Taniguchi, Noritake and Izumitani (1999) were the first to integrate location decision and capacity planning (number of berths) for public logistic terminals in urban areas that serve only the truck mode. Their proposed model selected logistic terminals from a set of predefined candidate locations and found the optimal number of berths for each terminal. Tang, Tang and Wang (2013) developed a model to find the best location for a logistics park, size of park and allocation of customers to it. They considered different layouts for the park and their model selected a lay out which can serve all demands. There has been limited work in capacity planning of intermodal terminals (Ballis \& Golias, 2004; Nocera, 2009). To date, no study has examined intermodal terminal location and terminal size jointly.

\subsubsection{Competitive location}

All of the aforementioned studies addressed the problem of designing a new network without consideration of existing road networks and rail terminals. Marianov et al. (1999) developed a competitive hub location model that considered existing terminals in the network. They assigned the 
demand for each OD pair to a pair of potential hubs to maximize this newcomer's market share. Transportation cost was the main factor for these assignments. In 2009, Eiselt and Marianov proposed a model of competitive hub location problem by incorporating a gravity model based on the work of Huff (1964). They allocated the demand to pairs of new hubs based on their attractions to maximize market share for the new hubs. Huff's gravity model is a popular approach for estimating the captured market share by a facility. Based on this model, the probability that a customer chooses a facility is proportional to the attractiveness of the facility and is inversely proportional to the distance to the facility. Eiselt and Marianov (2009) mentioned that their model is suitable for a new incoming airline that has to compete with existing airlines. Chiranjivi (2008) studied the environmental impact of adding a new terminal to an existing rail-highway network. They introduced factors that made a terminal attractive and investigated the effects of the new terminal on accessibility and mobility of the intermodal network. Gelareh et al. (2010) studied the competitive hub location for a liner shipping network. They considered a newcomer liner service provider which has to compete with existing liner service companies. They introduced an attraction function to estimate the total captured market share by a new terminal by considering the travel time from the origin to the destination using that specific terminal and transportation rate. Lüer-Villagra and Marianov (2013) formulated a new competitive hub location problem to find optimal locations for a new airline company and optimal pricing to maximize their profits. They modeled consumers' behaviors using the Logit discrete choice model.

Table 1 provides a summary of capabilities of previous models and this study's proposed model, which extends the work of Eiselt and Marianov (2009) by considering more than one mode for a competitive p-hub network as well as uncertainty in demand. It enhances previous models in the area of intermodal terminal location problem by considering competition. As explained previously, competition involves new incoming terminals competing against existing terminals in the network for market share. Although Limbourg and Jourquin (2009) considered existing intermodal terminals in their model, they did not consider competition between the new terminals and existing ones. To our knowledge, competition has not been addressed in any intermodal network design studies. As indicated in Table 1, this paper advances the modeling of intermodal network design by considering competition and the joint location and terminal throughput capacity decisions. Additionally, it is the first intermodal network design study to use robust optimization to address uncertainty in demand. A brief overview of robust optimization as well as relevant literature is presented in the next subsection.

\subsection{Background (robust optimization)}

In developing models for real world systems, researchers often face incomplete and noisy data (Mulvey et al., 1995). To address uncertainty in data, researchers have developed a technique called robust optimization. It deals with uncertainty by considering a set of finite discrete scenarios for the parameter with noisy data and finds a solution that is near-optimal for any realization of scenarios (Snyder \& Daskin, 2005).

Min-max regret and minimum expected regret are the two common robust optimization approaches (Kouvelis \& Gu, 1997). To understand these approaches, consider a situation where $S$ denote a set of $s$ finite scenarios for the uncertain parameter and $x$ represents a feasible solution for the robust problem.

Let $Z_{s}(x)$ represents the solution of the feasible point $x$ in scenario $s$ and $Z_{s}^{*}$ represents the optimal solution for scenario $s$ (over all $x$ ). The min-max regret finds a solution which minimizes the maximum "regret" value for all scenarios and is formulated as follows.

$$
\min _{x \in X}\left(\max _{s \in S}\left(Z_{s}(x)-Z_{s}^{*}\right)\right)
$$


The "regret" represents the difference between $Z_{s}(x)$ and $Z_{s}^{*}$. For maximization problems, the regret is negative for each scenario; thus, for these problems, the objective of the robust model is to maximize the minimum regret. For situations where there is information about the probability of each scenario occurring, the minimum expected regret approach is preferred, which will find the near-optimal solution by minimizing the expected regrets over all scenarios (Daskin et al., 1997).

There are a few studies in the literature that have utilized robust optimization to address uncertainty for hub location problems. Huang and Wang (2009) were the first to use robust optimization to find the near-optimal hub-and-spoke network design for an airline given uncertain demands and costs. They developed a multi-objective model and minimized total cost for all scenarios. Makui et al. (2012) developed a robust optimization model for the multi-objective capacitated p-hub location problem to deal with uncertainty in the demands for each OD pair and the processing time for each commodity at a hub. In the area of competitive location problem, Ashtiani et al. (2013) were the first to develop a robust optimization model for the leader-follower competitive facility location problem. This class of problems deals with the situation where the leader and follower have existing facilities, and the follower wants to open some new facilities, but the number of new facilities for the follower to open is uncertain. The objective of the leader-follower model is to maximize the market share for the leader after the follower has opened its new facilities.

Table 1 Comparison of current paper's and related studies' capabilities

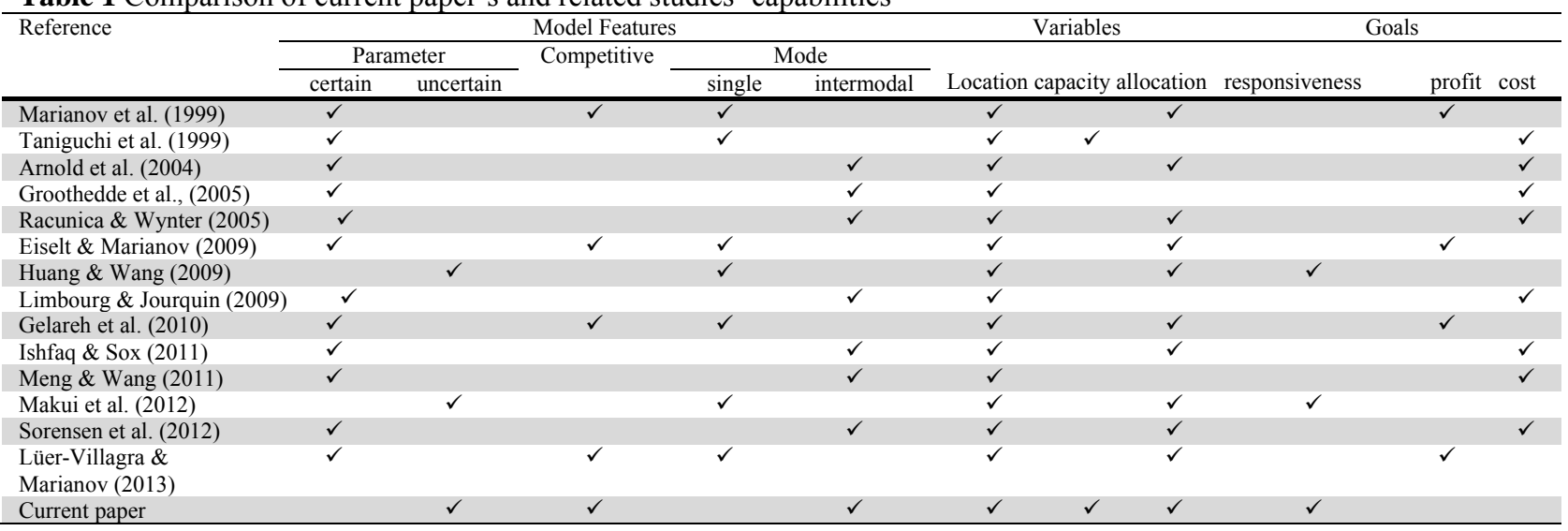

\section{Modeling framework}

Consider a railroad company's rail-highway intermodal network that has competing railroad companies' infrastructure. Let $G\left(N_{1}, A_{1}\right)$ and $G\left(N_{2}, A_{2}\right)$ represent road and rail networks, respectively. Thus, $N_{1}$ represent cities, and $N_{2}$ represent intermodal terminals in the rail network. Similarly, $A_{1}$ represent the highway links in the highway network, and $A_{2}$ represent the railway links in the rail network. A shipment from origin $i$ to destination $j$ can be transported either directly by truck only via links on $A_{1}$ or by a combination of truck and rail (i.e. intermodal). The intermodal option involves trucks transporting cargo from origin $i$ to terminal $k$ via links on $A_{1}$, then trains transporting cargo from terminal $k$ to terminal $m$ via links on $A_{2}$, and finally trucks transporting cargo from terminal $k$ to destination $j$ via links on $A_{1}$. Let $W$ represent the set of selected OD pairs with demands between them from $N_{1}$ cities.

Suppose a railroad company decided to expand its network by opening $q$ new terminals from $N_{\text {new }}$ candidate locations. It wants the new terminals to attract as much demand as possible (i.e. increase its market share). However, the railroad company already has $N_{e o}$ terminals in the proximity of the 
market area for candidate locations and its competitors have $N_{e c}$ terminals in the same area. Although there are more terminals operating in the network, the new incoming terminals only have to compete against those in the sets $N_{e o}$ and $N_{e c}$; it is assumed that only those terminals located in the proximity of the candidate locations will have a direct impact on the market share of new incoming terminals. Thus, $N_{2}$, as defined previously, includes the railroad company's and competitors' existing terminals around candidate locations, the new terminals at candidate locations, and all other terminals in the network. Logically, the company should locate the new terminals at some distance, $M$, away from its existing ones to avoid serving the same market. Note that $M$ may have different values based on the demographics of different parts of the network. According to Cunningham (2012) $M$ has a value of 100 miles for the Eastern parts of the U.S. and 250 miles for the Western parts. Thus, the decision that the railroad company has to make is where to open the new terminal(s). Let this decision be defined by the binary decision variable $y_{k}$, which is equal to 1 if the candidate terminal $k \in N_{\text {new }}$ is selected. In a prescreening process, candidate terminals with a distance of less than $M$ from the company's existing terminals are excluded from the list of eligible candidate terminals. If location $k$ is selected, then the binary decision variable $x_{k m}$ indicates whether there is a connection between terminals $k$ and $m$. If neither $k$ nor $m$ is open, then $x_{k m}$ cannot be 1 . For existing terminals $(k, m), x_{k m}$ is 1 .

Shipments going from origin $i$ to destination $j$ can be transported via multiple routes if there are several intermodal terminals available. The utility (i.e. attractiveness) of the intermodal option via the pair of terminals $(k, m)$ for shipments going from origin $i$ to destination $j$ can be defined as follows.

$$
u_{i j k m}=\frac{1}{\left(d_{i k}+d_{k m}+d_{m j}\right)^{\alpha}}
$$

where $d_{i k}$ and $d_{m j}$ denote the delivery and pickup drayage distances, respectively, and $d_{k m}$ is the linehaul distance. The term $\alpha$ in Equation 2 can be used to give less significance to those facilities that are far from the origin and/or destination (Huff, 1964). In this study, a simple inversely proportional relationship is assumed; thus $\alpha$ is set to 1 . Similarly, the utility of the truck-only option for shipments going from origin $i$ and destination $j$ is defined as follows.

$$
v_{i j}=\frac{1}{d_{i j}}
$$

The Huff gravity functions, Eq. (2) and Eq. (3), can be used to compute the utilities of the two competing modes, intermodal and truck-only. Using these utilities, the probability that a shipper chooses a particular mode can be calculated using the Logit choice model. The probability that a shipper uses the intermodal option via terminals $(k, m)$ to transport cargo from origin $i$ to destination $j$ is:

$$
p_{i j k m}=\frac{u_{i j k m} x_{k m}}{\sum_{(k \text { or } m) \in\left\{N_{\text {new }}\right\}} u_{i j k m} x_{k m}+\sum_{(k, m) \in\left\{N_{2}-N_{\text {new }}\right\}} u_{i j k m} x_{k m}+v_{i j}}
$$

Similarly, the probability that shippers choose the truck-only option to move their cargo is:

$$
p_{i j}=\frac{v_{i j}}{\sum_{(k \text { or } m) \in\left\{N_{\text {new }}\right\}} u_{i j k m} x_{k m}+\sum_{(k, m) \in\left\{N_{2}-N_{\text {new }}\right\}} u_{i j k} x_{k m}+v_{i j}}
$$


It is assumed that all demands are met. That is, for a specific OD pair $(i, j)$, the sum of all probabilities is equal to $1\left(\sum_{(k, m)} p_{i j k m}+p_{i j}=1\right)$.

In this study, we accounted for the fact that future freight demand is uncertain and that we have a finite set of demand scenarios. Let these scenarios be denoted as $S=\{1 . . s\}$. The demand for OD pair $(i, j)$ under scenario $s$ is denoted as $h_{i j}^{s}$. The probability that demand between nodes $i$ and $j$ is served by the intermodal option via terminals $(k, m)$ is $p_{i j k m}$. It follows that the total demand (i.e. market share) captured by terminals $(k, m)$ for OD pair $(i, j)$ under scenario $s$ is $h_{i j}^{s} p_{i j k m}$. The higher the probabilities for pairs of terminals $(k, m)$ as computed by Equation (4), the more demand the company will attract and thus increase its market share when either $k$ or $m$ is a new terminal.

In addition to determining the locations for the new terminals, our model also seeks to determine the annual throughput capacity, $z_{k}$, for the new terminal $k$ which depends on its total attracted demand. This capacity needs to be sufficiently large to accommodate all demand scenarios. The objective of this problem is to maximize the new terminals' profits for all scenarios by maximizing the minimum regret. The revenue generated by terminal $k$ per container is denoted as $r_{k}$. It is a fee that a shipper pays to the terminal for handling the container. There is an annual fixed cost $f_{k}$ to operate the terminal, in addition to an operating cost $c_{k}$ for handling the container.

\subsection{Mathematical formulation}

The mathematical model for the max-min intermodal terminal location problem in a competitive environment can be formulated as follows (P1).

P1:

$\max Z$

subject to:

$$
\begin{aligned}
& \sum_{(i, j) \in W,(k \text { or } m) \in N_{\text {new }}} h_{i j}^{s} p_{i j k m} r_{k}-\sum_{k \in N_{\text {new }}} f_{k} y_{k}-\sum_{k \in N_{\text {new }}} c_{k} z_{k}-O_{s}^{*} \geq Z, \quad \forall s \in S \\
& p_{i j k m}=\frac{u_{i j k m} x_{k m}}{\sum_{(k \text { or } m) \in N_{\text {new }}} u_{i j k m} x_{k m}+\sum_{(k, m) \in\left\{N_{2}-N_{\text {new }}\right\}} u_{i j m} x_{k m}+v_{i j}}, \quad \forall(i, j) \in W,(k \text { or } m) \in N_{\text {new }} \\
& \sum_{k \in N_{\text {new }}} y_{k}=q, \\
& x_{k m} \leq y_{k}, \quad \forall k \in N_{\text {new }}, m \in N_{2} \\
& x_{k m} \leq y_{m}, \quad \forall m \in N_{\text {new }}, k \in N_{2} \\
& \sum_{(i, j) \in W, m \in N_{2}}\left(p_{i j k m} h_{i j}^{s}+p_{i j m k} h_{i j}^{s}\right) \leq z_{k}, \quad \forall k \in N_{\text {new }}, \forall s \in S \\
& y_{k}, x_{k m} \in\{0,1\}, z_{k} \geq 0, \quad k \in N_{\text {new }}, m \in N_{2}
\end{aligned}
$$

The objective function (6) maximizes the minimum regret. $O_{s}^{*}$ in constraints (7) is the optimal objective function for scenario $s$ that is obtained by considering scenario $s$ alone. The regret associated with each scenario is the difference between the total profit of new terminals comprising all scenarios and $O_{s}^{*}$. Constraints (7) show that each scenario's regret is greater than a minimum regret. Constraints 
(8) compute the probability that the intermodal option is used with the demand allocated to each pair of open terminals. Constraints (9) guarantee that $q$ terminals will be selected. Constraints (10) and (11) ensure that the variable $x_{k m}$ is 0 if either terminal $k$ or $m$ is not selected. Constraints (12) define throughput capacities of selected terminals. Constraints (13) define the range of the decision variables. To obtain the regret of scenario $s$ in constraints (7), $O_{s}^{*}$ is determined by solving the following model (P2).

P2:

$O_{s}: \operatorname{Max} \sum_{(i, j) \in W,(k \text { or } m) \in N_{\text {new }}} h_{i j}^{s} p_{i j k m} r_{k}-\sum_{k \in N_{\text {new }}} f_{k} y_{k}-\sum_{k \in N_{\text {new }}} c_{k} z_{k}$

subject to: Eqs. (8) - (13)

The first term in objective function (14) is the total revenue generated by the new terminals. The second term is the annual fixed cost of operating the terminals, and the third term is the variable cost of operating the terminal. If the decision maker knows the probability of each scenario occurring, then the objective of the robust optimization model would be to minimize the expected regret. As mentioned previously, the regret for problems with maximization objective is negative so the robust model's objective function is to maximize the expected regret. If scenario $s$ occurs with probability $\beta_{s}$ and $R_{s}$ shows its related regret, then the maximum expected regret model is defined as follows (P3).

P3:

$O_{\text {exp }}: \max \sum_{s} \beta_{s} R_{s}$

subject to:

$$
\begin{aligned}
& \mathrm{R}_{\mathrm{s}}=\sum_{(i, j) \in W,(k \text { or } m) \in N_{\text {new }}} h_{i j}^{s} p_{i j k m} r_{k}-\sum_{k \in N_{\text {new }}} f_{k} y_{k}-\sum_{k \in N_{\text {new }}} c_{k} z_{k}-O_{s}^{*}, \quad \forall s \in S \\
& E q S .(8)-(13)
\end{aligned}
$$

$O_{\text {exp }}$ in Eq. (15) maximizes the expected regret over all scenarios and $\mathrm{R}_{\mathrm{s}}$ in Eq. (16) is the regret of each scenario.

\section{Solution method}

The aforementioned model is a nonlinear integer program, which is NP-hard (Krumke, 2004) and is not solvable by standard Mixed Integer Nonlinear Programing solvers (Eiselt \& Marianov, 2009) while it may be possible to find the exact solutions for realistic-sized problems by exhaustive enumeration, such an approach will likely take days to solve, even with today's high performance desktops and workstations. For this reason, there is an increasing body of work that focuses on researching efficient algorithms using meta-heuristics such as tabu search and genetic algorithm to find the exact solutions for strategic problems (e.g., Ishfaq \& Sox, 2011; Meng \& Wang, 2011). In this research, a simulated annealing algorithm is proposed to find the optimal solutions for the three models discussed above: P1, $\mathrm{P} 2$ and $\mathrm{P} 3$.

\subsection{Background on simulated annealing (SA) algorithm}

Kirkpatrick et al. (1983) were the first to propose SA to solve combinatorial optimization problems. The SA algorithm begins with an initial feasible solution and then its neighborhood is randomly 
searched for improvement. If the objective function improves, the solution is accepted and it becomes the new solution from which the search continues. Otherwise, it will accept a non-improving solution with a probability determined by the Boltzmann function $\exp (-\Delta / T)$, where $\Delta$ is the difference between the objective functions of two consecutive iterations and $T$ is the temperature at that iteration. This probability is high at the beginning of the algorithm. It increases the chance of accepting a worse solution to avoid getting trapped in a local solution, but it decreases as the algorithm proceeds (i.e. cools down to its frozen temperature). Readers are referred to Kirkpatrick et al. (1983) for a complete description of the SA algorithm.

For SA, the cooling schedule requires a starting temperature $T_{0}$, cooling rate $\gamma$, maximum number of iterations at each temperature $K_{\max }$ and the stopping number $\sigma . T_{0}$ is selected so that the probability of accepting non-improving solutions is $P_{0}$. A number of non-improving neighborhoods for the initial solution which is a fraction of the neighborhood size (5\% to $10 \%)$ are evaluated and their average cost increase (for cost minimization problems) $\overline{\Delta C}$ is computed. Then $T_{0}$ is computed based on this formula $\exp \left(-\overline{\Delta C} / T_{0}\right) \approx P_{0}$ [39]. A simple decay function of the parameter $\gamma$ updates the temperature at the end of each epoch $r$; i.e. $T(r+1)=\gamma T(r)$. The value of $\gamma$ is typically between 0.85 and 0.95 , with higher values generating more accurate results but with a lower convergence rate. The number of iterations $K_{\max }$ is determined by the neighborhood size. The algorithm terminates when no improvement is found in a specific number of temperatures $\sigma$.

SA has been applied to a number of facility location problems and hub location problems (Murray \& Church, 1996, Ernst \& Krishnamoorthy, 1999, Arostegui et al., 2006). Drezner et al. (2002) were the first to apply SA for solving Huff-like competitive facility location problems. They proposed five different algorithms and showed that SA has promising results. The next subsection discusses how the SA algorithm was applied to solve the developed models.

\subsection{Proposed simulated annealing algorithm}

In this subsection, how the SA was adapted to solve P2 is first discussed. Then, how it was modified to solve P1 and P3 is presented. A feasible solution for P2 is any configuration of $q$ new terminals and their capacities. Thus, among the candidate locations, the ones that are furthest from the company's existing terminals are selected as the initial set of terminals. In this problem, constraints (10) and (11) may be replaced by the following equation:

$x_{k m}=\min \left\{y_{k}, y_{m}\right\} \quad \forall(k$ or $m) \in N_{\text {new }}$

Eq. (17) indicates that $x_{k m}$ values are determined based on the initial terminal set. The parameters $u_{i j k m}$, $p_{i j k m}$ and $z_{k}$ are computed based on $y$ and $x$ values. $u_{i j k m}$ values are determined based on the distances to terminals regardless of the terminal being open or not; thus, they remain constant through the end of the algorithm. The complete neighborhood for a solution is the set of all solutions found by closing one terminal and opening a closed terminal from the set of unselected terminals. For this problem, the neighborhood size is $q^{*}\left(N_{\text {new }}-q\right)$. Given an incumbent solution, one of the neighboring solutions is selected by closing the terminal with the highest fixed and variable costs and opening a candidate terminal that is furthest from the set of unselected terminals. From this new terminal set (solution), the $x_{k m}, p_{i j k m}$ and $z_{k}$ values are computed and objective function (14) is evaluated.

For this problem, $10 \%$ of a neighborhood is evaluated to compute $T_{0}$. Initial testing found that the SA algorithm obtained optimal solutions for small cases with $\gamma=0.9$ and $\sigma=3$. Thus, these values were 
used for larger problems as well, but with a small increase in $\sigma$ based on the problem size. The overall algorithm for P2 is outlined in Fig. 1.

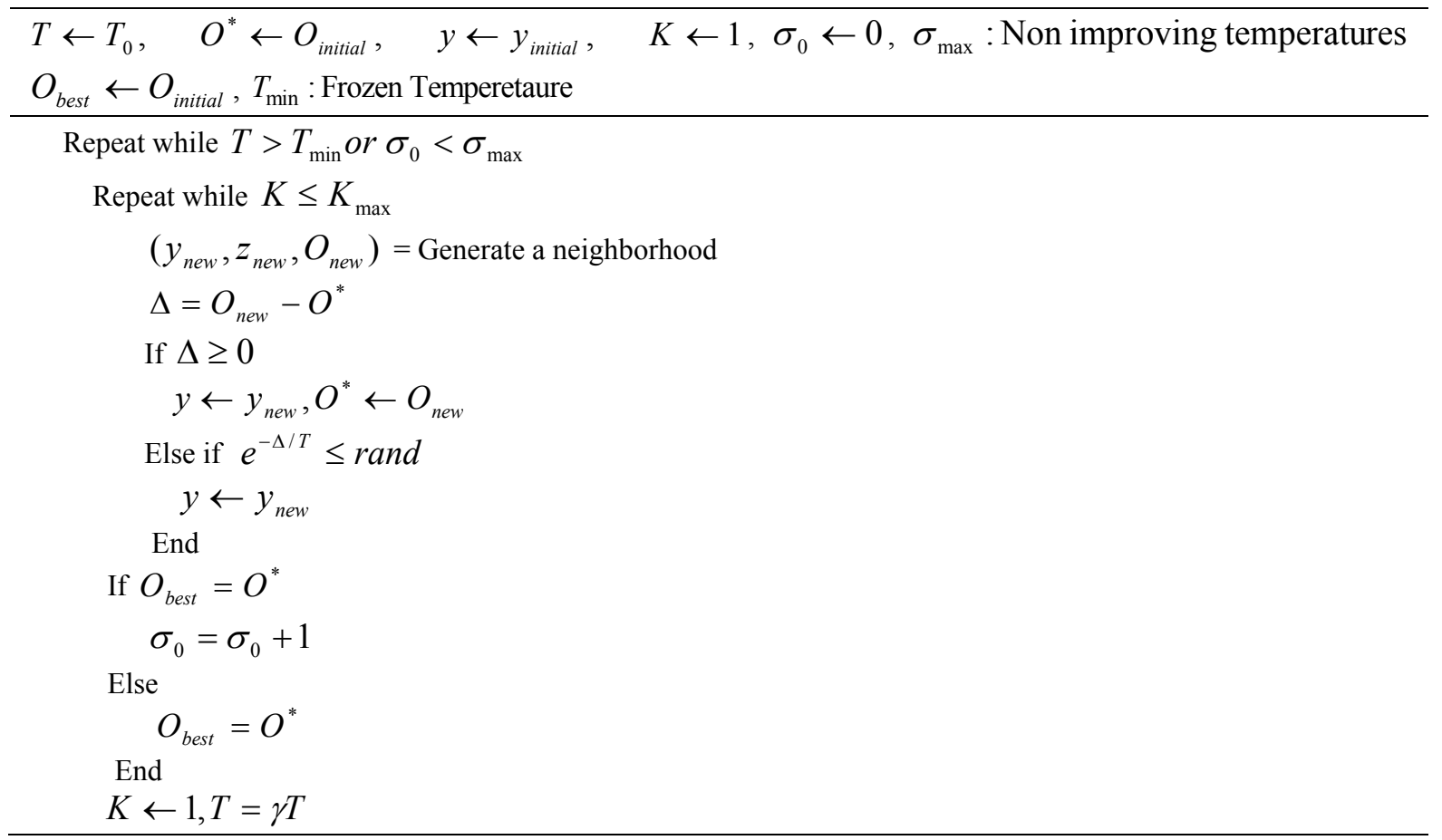

Fig. 1 Simulated annealing algorithm for solving P2

The SA algorithm discussed above can also be used to solve P1 and P3 with a minor change. The capacity constraints (12) in P1 and P3 determine the throughput capacity of open terminals under each scenario. It should be sufficiently large to accommodate any realization of demand values; thus, at each iteration of the SA algorithm the throughput capacity $z_{k}$ for terminal $\mathrm{k}$ with $y_{k}=1$ is computed as $\max _{S}\left(\sum_{(i, j) \in w, m \in N_{2}}\left(p_{i j k m} h_{i j}^{s}+p_{i j m k} h_{i j}^{s}\right)\right)$.

\section{Computational experiments}

The SA algorithm was coded in MATLAB R2012a, and the developed algorithm for P2 was tested on several randomly generated networks. Its performance was compared against GAMS/BARON solutions. The Branch-And-Reduce Optimization Navigator (BARON) is a GAMS commercial solver designed to find the global solution of Non-Linear Programs (NLP) and Mixed Integer Non-Linear Programs (MINLP) (Sahindis, 2013). All experiments were run on a desktop computer with an Intel Core 2 Duo $2.66 \mathrm{GHz}$ processor and $8 \mathrm{~GB}$ of RAM and their computational times were reported.

In order to examine the performance of SA for P2, 20 experiments with different problem sizes were randomly generated. The parameters for these problems are given in Table 2. These values were selected to reflect real world scenarios. The size of the test networks range from 4 to 15 existing terminals, 2 to 15 candidate locations, and 1 to 4 new terminals to open. Theoretically, $q$ can be changed from 1 to $N$ new. However, in reality, it is likely that the number of terminals that can be opened and be profitable based on the demand OD pair pattern, shipper's expenditures, existing terminals in the market area, and terminal costs will be fewer than $N$ new. Thus, for each test network, only a limited range of $q$ is solved to find their optimal locations. 
Table 2

Values of parameters used in numerical experiments

\begin{tabular}{ll}
\hline Parameter & Value \\
\hline Highway miles & Normal $(1,000,100)$ \\
Line haul miles & Normal $(700,100)$ \\
Drayage miles & Normal $(450,100)$ \\
Fixed cost (\$ per year) & Uniform $(10,000,30,000)$ \\
Variable cost (\$ per container) & Uniform $(10,20)$ \\
Revenue (\$ per container) & Uniform $(20,30)$ \\
Distance (miles) between competing terminals (existing and new) & Normal $(400,100)$ \\
Demand (containers) & Uniform $(100,300)$ \\
\hline
\end{tabular}

Table 3 summarizes the results of the test problems. Column 1 indicates the experiment number. Columns 2, 3, and 4 show number of existing terminals in the competition area, number of existing terminals far from the competition area, and number of candidate locations for the new terminals, respectively. $q$ in column 5 indicates the number of new terminals to be opened. Columns 6 and 7 show the objective function values found by SA $\left(Z_{S A}\right)$ and GAMS $\left(Z_{\text {GAMS }}\right)$ respectively. Column 8 shows the gap between the $Z_{\mathrm{SA}}$ and $Z_{\mathrm{GAMS}}$; gap is computed as $100 *\left(\frac{z_{G A M S}-z_{S A}}{z_{\text {GAMS }}}\right)$. The last two columns show the execution time in seconds of SA $\left(t_{S A}\right)$ and GAMS $\left(t_{\text {GAMS }}\right)$, respectively.

It can be seen in Table 3 that the developed SA obtained the same objective function values as GAMS for all experiments. The asterisk in column 6 indicates that the network with the corresponding $q$ new terminals yield the optimal profit. For example, for a network with 5 existing terminals and 5 candidate locations (experiment number 6 to 9), 3 new terminals yield the maximum profit for the company. The execution times indicated that the SA algorithm can obtain solutions in much shorter time than GAMS for larger problems. The execution time for GAMS grows exponentially with the problem size. It takes more than 6 hours for GAMS to find the optimal solution for a problem with 50 OD pairs, 10 existing terminals and 15 candidate locations for the new terminals while SA obtains the same results in a few seconds. GAMS was not able to obtain a solution for problems with more than 10 existing terminals and 15 candidate locations due to out of memory error. To show the application of the developed model for larger problems, the two case studies discussed in the next subsections are solved using our developed SA method.

Table 3

Performance of SA compared against GAMS for test problems

\begin{tabular}{|c|c|c|c|c|c|c|c|c|c|}
\hline Exp.\# & $N_{\text {existing-competitin }}$ & $N_{\text {existing-other }}$ & $N_{\text {new }}$ & $q$ & $Z_{S A}$ & $Z_{\text {GAMS }}$ & Gap(\%) & $t_{S A}(\mathrm{~s})$ & $t_{\text {GAMS }}(s)$ \\
\hline (1) & (2) & (3) & (4) & (5) & (6) & (7) & (8) & (9) & (10) \\
\hline 1 & 2 & 2 & 2 & 1 & $6,810^{*}$ & 6,810 & 0 & 1.6 & 1 \\
\hline 2 & 2 & 2 & 2 & 2 & 1,425 & 1,425 & 0 & 1.2 & 0.55 \\
\hline 3 & 3 & 2 & 3 & 1 & 17,715 & 17,715 & 0 & 2.6 & 14.18 \\
\hline 4 & 3 & 2 & 3 & 2 & $25,205^{*}$ & 25,205 & 0 & 3.1 & 14.45 \\
\hline 5 & 3 & 2 & 3 & 3 & 19,816 & 19,816 & 0 & 3.05 & 37 \\
\hline 6 & 3 & 2 & 5 & 1 & 18,558 & 18,558 & 0 & 2.09 & 25.3 \\
\hline 7 & 3 & 2 & 5 & 2 & 25,194 & 25,194 & 0 & 2.18 & 27.1 \\
\hline 8 & 3 & 2 & 5 & 3 & $26,133 *$ & 26,133 & 0 & 2.15 & 28.2 \\
\hline 9 & 3 & 2 & 5 & 4 & 18,859 & 18,859 & 0 & 2.1 & 32 \\
\hline 10 & 4 & 5 & 6 & 1 & 21,548 & 21,548 & 0 & 2.33 & 367 \\
\hline 11 & 4 & 5 & 6 & 2 & $32,354 *$ & 32,354 & 0 & 2.19 & 440 \\
\hline 12 & 4 & 5 & 6 & 3 & 31,097 & 31,097 & 0 & 2.44 & 520 \\
\hline 13 & 5 & 7 & 8 & 1 & 24,494 & 24,494 & 0 & 3.7 & 3663 \\
\hline 14 & 5 & 7 & 8 & 2 & $39,303 *$ & 39,303 & 0 & 2.97 & 3605 \\
\hline 15 & 5 & 7 & 8 & 3 & 31,850 & 31,850 & 0 & 2.6 & 3720 \\
\hline 16 & 7 & 8 & 10 & 1 & 14,214 & 14,214 & 0 & 3.4 & 15121 \\
\hline 17 & 7 & 8 & 10 & 2 & $20,343 *$ & 20,343 & 0 & 3.25 & 14700 \\
\hline 18 & 7 & 8 & 10 & 3 & 19,384 & 19,384 & 0 & 3.29 & 16850 \\
\hline 19 & 7 & 3 & 15 & 1 & $4,802^{*}$ & 4,802 & 0 & 3.2 & 18050 \\
\hline 20 & 7 & 3 & 15 & 2 & $1,272.6$ & $1,272.6$ & 0 & 5.6 & 25265 \\
\hline
\end{tabular}




\subsection{Larger-sized instances}

The robust models P1 and P3 were applied to two larger-sized case studies. The first case study involves an actual intermodal network in the U.S. and a set of freight demand scenarios derived from the Freight Analysis Framework (FAF3) (Battelle, 2011). The FAF3 database is provided by the U.S. Department of Transportation and it provides estimates of freight tonnage, value, and domestic tonmiles by region of origin and destination, commodity type, and mode, as well as state-to-state flows. To demonstrate the usability and generality of the developed model and solution approach, the second case study uses a larger random network configuration, as well as random demand volume and OD patterns.

\subsubsection{Case study 1}

This case study involves an actual intermodal network in the U.S., east of the Mississippi River. In the study area, there are two Class 1 railroad companies, A and B. Company A is considering expanding its network by adding a new terminal in South Carolina (SC). The candidate locations are Greenville, North Augusta, Lexington, and Florence. According to FAF3, these cities have the highest freight flow in South Carolina. They also have a good accessibility to interstates. Currently, both railroad companies have 4 to 5 terminals in South Carolina and neighboring states and a total of 18 in the study network. The goal of this analysis is to identify the optimal location for the new terminal and its throughput capacity. Fig. 2 depicts the study area.

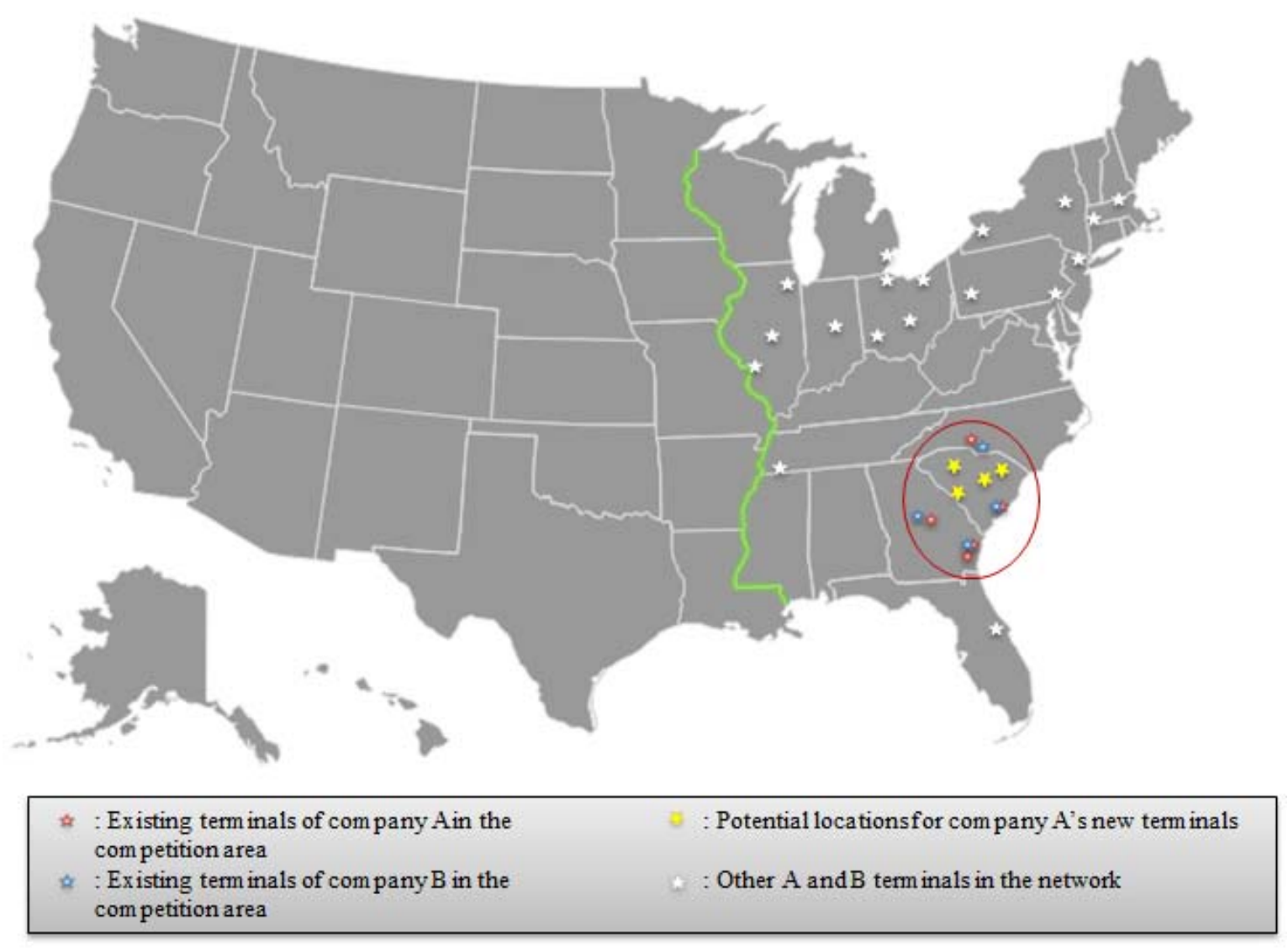

Fig. 2 Map of study area for case study 1

The analysis considered only domestic shipments that would use the intermodal option, which are those that need to be transported more than 750 miles and has an annual tonnage of more than 125 tons (ITIC 
manual, 2005). Live animals/fish, specific agricultural products, meat/seafood, alcoholic beverages, pharmaceuticals, plastics/rubber, wood products, newsprint/paper, paper articles, printed products, base metals, machinery, and furniture are the non-eligible commodities for intermodal transportation, and thus, were excluded from the analysis. After disaggregating the FAF3 data for 2040 using the proportional weighting method and using population as the surrogate variable, 482 eligible OD pairs were identified from/to SC counties to/from 16 states outside SC. Considering an average of 80,000 lbs as the maximum allowable weight for a 40-foot container, FAF3 commodity flows were converted to their equivalent container units. Fig. 3 shows the quantity of 2040 demand in number of containers for SC counties. As shown, Greenville, Charleston and their neighboring counties have the highest forecasted freight movement. Lexington and Richland counties are also forecasted to have high freight movement. Cost-of-living index was used to determine the relative relationship between the fixed costs and operating costs between the four candidate locations. Based on this index, Lexington is the most expensive county and parameters for the other three locations were computed based on the index. Google Maps was used to determine the drayage and line-haul distances.

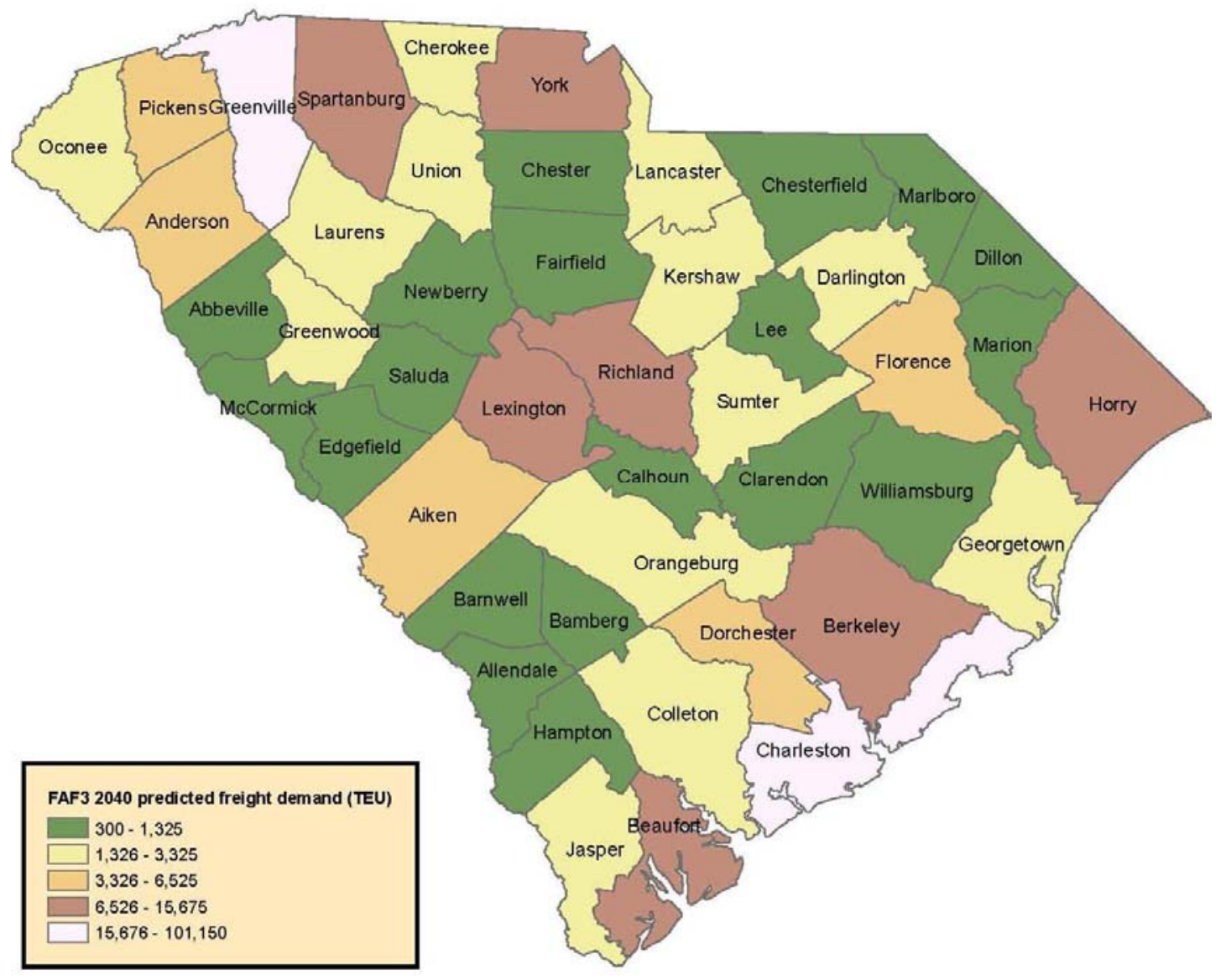

Fig. 3. FAF3 2040 predicted freight demand for SC counties.

Ten demand scenarios were considered, based on the FAF3 predicted values for 2040. Scenario 1 is the FAF3 2040 demand estimate. Scenarios 2 to 4 are those with demands 5, 10 and 20\% over the 2040 estimate. Scenarios 5 to 7 are those with demands 5, 10, and 20\% under the 2040 estimate. Scenarios 8 to 10 considered the possibility of new developments that may take place in the industrial counties. Table 4 shows the best location and its associated capacity for each scenario. If investment decisions are made using only the 2040 forecasted demand, then Greenville with a throughput capacity of 41,176 TEUs is the optimal location and size. However, that is not the case when other demand scenarios are considered, as illustrated in Table 4. If a terminal with a capacity of 41,176 TEU is built (based on the 2040 demand estimate) and scenario 2 occurred, then the terminal will not have enough 
capacity to meet the demand, 43,235 TEUs. This result shows that decision makers need to explicitly account for the different demand scenarios. The analysis showed that even if company A had the budget to build more than one new terminal, building just one new terminal is optimal because the profit decreases with each additional terminal.

Table 4

Results for individual scenarios

\begin{tabular}{|c|c|c|c|}
\hline Row & Scenario & Selected terminal & $\begin{array}{l}\text { Capacity } \\
\text { (TEU) }\end{array}$ \\
\hline 1 & FAF3 predicted demand for 2040 & Greenville & 41,176 \\
\hline 2 & $5 \%$ increase in the demand for 2040 & Greenville & 43,235 \\
\hline 3 & $10 \%$ increase in the demand for 2040 & Lexington & 44,850 \\
\hline 4 & $20 \%$ increase in the demand for 2040 & Lexington & 48,927 \\
\hline 5 & $5 \%$ decrease in the demand for 2040 & Greenville & 39,118 \\
\hline 6 & $10 \%$ decrease in the demand for 2040 & Greenville & 37,059 \\
\hline 7 & $20 \%$ decrease in the demand for 2040 & Greenville & 32,941 \\
\hline 8 & $\begin{array}{l}50 \% \text { increase in the demand in Charleston, Horry, Beaufort and } \\
\text { Berkeley counties }\end{array}$ & Lexington & 46,595 \\
\hline 9 & $\begin{array}{l}50 \% \text { increase in the demand in Lexington, Richland and Aiken } \\
\text { counties }\end{array}$ & Greenville & 42,960 \\
\hline 10 & $\begin{array}{l}30 \% \text { increase in the demand in Greenville, Spartanburg, York, } \\
\text { Richland, Lexington, Charleston, Berkeley, Beaufort and Horry } \\
\text { counties }\end{array}$ & Lexington & 50,215 \\
\hline
\end{tabular}

Table 5 presents the results for the robust models P1 and P3. Column 1 shows how many scenarios are considered for each experiment. Column 2 shows which scenarios are considered, i.e. 1-3 refers to scenarios 1 to 3 . Columns 3 and 4 indicate the optimal objective functions for P1 and P3, respectively. The selected site by P1 and P3 are presented in columns 5 and 6 and their associated capacities are shown in columns 7 and 8, respectively. The last two columns show the execution times of P1 and P3, respectively. Greenville is the optimal location, but its capacity changes with inclusion of different scenarios in the decision for both models. These results indicated that the demand scenarios play a key role in determining the throughput capacity of the terminal for both robust models. It is noted that in scenario 1 (row 1 of Table 4), almost half of the freight demands reside in the northern counties (i.e. Greenville, Spartanburg, York, Pickens and Anderson). Thus, Greenville was a suitable location to meet the demand for scenario 1 since it is located furthest north among the candidate locations.

Table 5

Solutions of the robust models: $\mathrm{Z}$ for $\mathrm{P} 1$ and $\mathrm{O}$ for $\mathrm{P} 3$

\begin{tabular}{cccccccccc}
\hline $\begin{array}{c}\# \text { of } \\
\text { scenarios } \\
(1)\end{array}$ & scenarios & $Z^{*}$ & $O_{\exp }^{*}$ & $y(Z)$ & $y\left(O_{\text {exp }}\right)$ & $z(Z)$ & $z\left(O_{\exp }\right)$ & $t_{Z}$ & $t_{O_{\exp }}$ \\
\hline 2 & $(2)$ & $(3)$ & $(4)$ & $(5)$ & $(6)$ & $(7)$ & $(8)$ & $(9)$ & $(10)$ \\
\hline 3 & $1-2$ & -146690 & -110020 & Greenville & Greenville & 43235 & 43235 & 8.62 & 7.26 \\
4 & $1-3$ & -293380 & -212850 & Greenville & Greenville & 45294 & 45294 & 9.71 & 9.04 \\
5 & $1-4$ & -586760 & -491980 & Greenville & Greenville & 49412 & 49412 & 10.14 & 10.31 \\
6 & $1-5$ & -733460 & -505480 & Greenville & Greenville & 49412 & 49412 & 11.36 & 11.83 \\
7 & $1-6$ & -880150 & -552190 & Greenville & Greenville & 49412 & 49412 & 12.76 & 13.83 \\
8 & $1-7$ & -1173500 & -587500 & Greenville & Greenville & 49412 & 49412 & 15.18 & 14.55 \\
9 & $1-8$ & -1173500 & -508380 & Greenville & Greenville & 49412 & 49412 & 48.78 & 16.35 \\
10 & $1-9$ & -1173500 & -476940 & Greenville & Greenville & 49412 & 49412 & 50 & 17 \\
\hline
\end{tabular}

To illustrate the impact of probabilities on site selection using P3, a set of four scenarios $(1,8,9$ and 10) with various probabilities was considered and the results were compared to those obtained by P1. Recall that Greenville was the optimal site for P1 regardless of probability values. It can be observed in Table 6 that Greenville is the optimal location with higher probabilities for scenarios 1 and 9, but Lexington became the optimal site when scenarios 8 and 10 have higher probabilities (highlighted in 
Table 6). This is because of the higher freight demands in central and southern counties (Richland, Lexington, Charleston, Berkeley, Beaufort and Horry) in scenarios 8 and 10. These results verified that demand scenarios and their probability values are significant factors in site selection.

Table 6

Impact of scenario probabilities on terminal selection

\begin{tabular}{cccccc}
\hline Experiment & \multicolumn{3}{c}{ Scenario probabilities } & \multicolumn{2}{c}{ Selected Terminal } \\
\cline { 2 - 5 } & Scenario 1 & Scenario 8 & Scenario 9 & Scenario 10 & Greenville \\
\hline 1 & 0.5 & 0.1 & 0.1 & 0.3 & Greenville \\
3 & 0.4 & 0.1 & 0.1 & 0.4 & Greenville \\
4 & 0.3 & 0.1 & 0.1 & 0.5 & Greenville \\
5 & 0.2 & 0.1 & 0.1 & $\mathbf{0 . 7}$ & Lexington \\
6 & 0.1 & $\mathbf{0 . 1}$ & 0.1 & $\mathbf{0 . 4}$ & Lexington \\
7 & 0.1 & $\mathbf{0 . 3}$ & 0.05 & $\mathbf{0 . 6}$ & Lexington \\
\hline
\end{tabular}

\subsubsection{Case study 2}

While case study 1 involves an actual intermodal network, its characteristics led to predictable results. To gain additional insights, case study 2 used a random network with various scenarios of OD pair patterns and demand volumes. The random network, generated on a 1,000 by 1,000 miles grid, has 15 existing terminals and 15 candidate locations. The objective was to find the optimal locations for up to 5 new terminals and their corresponding throughput capacities. Fig. 4 depicts the intermodal network utilized in case study 2, with the 15 candidate locations (with their IDs labeled) and 15 existing terminals. It was assumed that there exists 20 cities, located randomly within a radius of 100 miles around each existing and candidate terminal. Given a combined total of 30 existing and candidate terminals, there is a total 600 cities in the intermodal network. The locations of the cities, represented by $(\mathrm{x}, \mathrm{y})$ coordinates, were generated as follows.

$x=x_{t}+\beta \cos \theta, \quad y=y_{t}+\beta \sin \theta$

where $\beta$ is a random number between 0 and 100 which defines the distance (in miles) between the city and the terminal $t$, and $\theta$ is a random number between 0 and 360 degree. $\left(x_{t}, y_{t}\right)$ denotes the coordinates of the terminal $t$. 1000 OD pairs were randomly generated from the 600 cities with a Euclidean distance of more than 500 miles because the intermodal option is not applicable for shorter distances. Note that although there are 15 existing terminals in the network, each candidate terminal only has to compete with those located within a 300 miles radius from it.

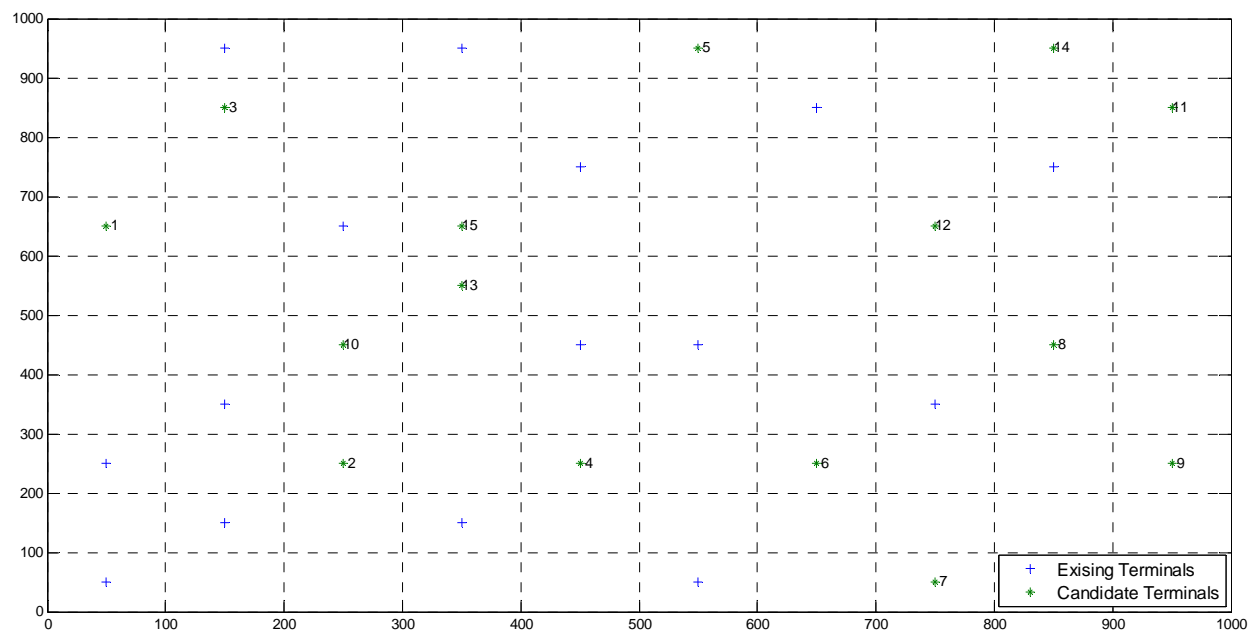

Fig. 4. Network layout for case study 2 
Monte Carlo simulation was used to generate up to 45 scenarios for the OD patterns and their demand volumes. Each scenario involves a different set of OD demand patterns and demand volume. The OD pairs were randomly selected from the set of 600 cities, and the demand volume was randomly generated from the distribution $\mathrm{U}[1,000,30,000]$. The case study consists of 9 experiments, with experiment 1 having 5 scenarios and each subsequent experiment has an additional 5 scenarios. It was assumed that shippers will not select the intermodal option if it has a drayage distance (either pickup or delivery) of more than 250 miles.

Table 7 presents the results of the case study. Column 1 shows the experiment number. Column 2 presents how many scenarios were considered for the robust problem. Columns 3 and 4 present the optimal terminals and their sizes, respectively. The results show that locations 9 and 11 were never selected because they are located in isolated areas of the network. Since they both have a much smaller market, it would not be profitable to open new terminals at these locations. On the other hand, locations 4, 7, 8, 10 and 15 were included in the optimal set in more than $50 \%$ of the experiments. Due to the randomness in OD patterns, the decision of where to locate new terminals is more complicated than when the OD patterns do not change. The results indicate that as the number of scenarios increases, the results of the robust model becomes more consistent. It be can be seen in Table 7 that as the number of scenarios gets higher, the solutions converge to a set of similar candidate locations. Specifically, it indicates that regardless of the scenario, candidate terminals 4, 7, 10 and 15 should be selected. An interesting observation from this case study is that the optimal locations could be identified using a smaller set of scenarios, but the optimal throughput capacities will need to use a much larger set of scenarios. In reality, it is unlikely to have scenarios where the OD demand patterns and demand volume differ drastically. Thus, it is expected that the developed robust model will be able to identify both optimal locations and terminal sizes using a relatively small number of scenarios.

Table 7

Solution of the robust model P1 for case study 2

\begin{tabular}{cccc}
\hline Experiment \# & \# of scenarios & Selected terminals & Throughput capacity (TEU) \\
\hline 1 & 5 & $7,10,14$ & $8,408,300 ; 4,445,800 ; 7,434,700$ \\
2 & 10 & $1,4,7,10,15$ & $4,872,100 ; 2,817,200 ; 7,779,800 ; 5,130,000 ; 441,300$ \\
3 & 15 & $1,6,10,14,15$ & 625,$199 ; 7,735,600 ; 3,596,500 ; 6,790,600 ; 3,813,900$ \\
4 & 20 & $3,4,7,8,12$ & $6,898,000 ; 4,335,000 ; 7,472,000 ; 15,674,000 ; 799,400$ \\
5 & 25 & $5,8,10,12,15$ & $15,008,000 ; 73,300,000 ; 4,576,000 ; 7,224,000 ; 5,156,000$ \\
6 & 30 & $2,7,8,10,15$ & $3,482,000 ; 8,353,000 ; 15,369,000 ; 4,119,000 ; 5,344,000$ \\
7 & 35 & $3,4,7,8,12$ & $7,430,000 ; 4,469,000 ; 15,616,000 ; 7,961,000 ; 7,812,000$ \\
8 & 40 & $4,7,8,10,15$ & $5,759,000 ; 15,224,000 ; 8,557,000 ; 5,436,000 ; 4,985,000$ \\
9 & 45 & $4,7,10,13,15$ & $15,325,000 ; 15,623,000 ; 4,225,000 ; 3,481,000 ; 3,276,000$ \\
\hline
\end{tabular}

\section{Managerial implications}

To gain insights on the implications of different managerial actions, two additional situations were analyzed. The first involves investigating the sensitivity of drayage distance on a terminal's ability to capture market share, and the second involves investigating the managerial option of closing an existing terminal and opening 1 or 2 new terminals at the candidate locations. The analysis was applied using the same network used for case study 1 and the 2040 FAF3 predicted freight flow for South Carolina. In the proposed model, shipments going from $i$ to $j$ are allocated to terminals $(k, m)$ based on their utility. The longer the drayage distances, from origin $i$ to terminal $k$ and from terminal $m$ to destination $k$, the less attractive the terminal pair $(k, m)$ is to shippers. To test the sensitivity of drayage distance on a terminal's ability to capture market share, we analyzed scenarios where shippers have a threshold on the maximum drayage distance they are willing to consider. In other words, we considered scenarios where shippers will only consider a terminal pair if their resulting drayage distances is less than their desired threshold. From the modeling standpoint, we effectively set the utility of terminals $(k, m)$ to 0 if its drayage distances exceed the threshold. Table 8 presents the results 
of this analysis. Column 1 shows the different drayage distance thresholds considered. Column 2 shows how many new terminals will be opened. Columns 3 and 4 present the company's intermodal share and the competitor's intermodal share, respectively. Column 5 shows the remaining percentage of shipments using the truck-only option. The last column shows the obtained best locations for new terminals.

\section{Table 8}

Effect of drayage distance thresholds on intermodal market shares and locations

\begin{tabular}{|c|c|c|c|c|c|}
\hline $\begin{array}{l}\text { Drayage Distance } \\
\text { threshold (miles) }\end{array}$ & \# of new terminals & $\begin{array}{l}\text { Own company's } \\
\text { intermodal share }\end{array}$ & $\begin{array}{c}\text { Competitor's } \\
\text { intermodal share }\end{array}$ & $\begin{array}{l}\text { Truck only } \\
\text { modal share }\end{array}$ & Selected terminals \\
\hline \multirow{4}{*}{100} & 1 & $27 \%$ & $19 \%$ & $54 \%$ & Greenville \\
\hline & 2 & $33 \%$ & $18 \%$ & $49 \%$ & Greenville, Florence \\
\hline & 3 & $35 \%$ & $18 \%$ & $47 \%$ & $\begin{array}{c}\text { Greenville, Florence, } \\
\text { Augusta }\end{array}$ \\
\hline & 4 & $37 \%$ & $17 \%$ & $46 \%$ & All \\
\hline \multirow{4}{*}{250} & 1 & $50 \%$ & $30 \%$ & $20 \%$ & Lexington \\
\hline & 2 & $53 \%$ & $27 \%$ & $20 \%$ & Lexington, Augusta \\
\hline & 3 & $56 \%$ & $24 \%$ & $20 \%$ & $\begin{array}{c}\text { Lexington, Augusta, } \\
\text { Greenville }\end{array}$ \\
\hline & 4 & $59 \%$ & $22 \%$ & $19 \%$ & All \\
\hline \multirow{4}{*}{350} & 1 & $50 \%$ & $31 \%$ & $19 \%$ & Lexington \\
\hline & 2 & $53 \%$ & $28 \%$ & $19 \%$ & Augusta, Lexington \\
\hline & 3 & $56 \%$ & $26 \%$ & $18 \%$ & $\begin{array}{c}\text { Lexington, Augusta, } \\
\text { Greenville }\end{array}$ \\
\hline & 4 & $58 \%$ & $24 \%$ & $18 \%$ & All \\
\hline \multirow{4}{*}{500} & 1 & $51 \%$ & $31 \%$ & $18 \%$ & Augusta \\
\hline & 2 & $54 \%$ & $29 \%$ & $17 \%$ & Augusta, Lexington \\
\hline & 3 & $56 \%$ & $27 \%$ & $17 \%$ & $\begin{array}{l}\text { Florence, Augusta, } \\
\text { Lexington }\end{array}$ \\
\hline & 4 & $58 \%$ & $25 \%$ & $17 \%$ & All \\
\hline
\end{tabular}

It can be seen in Table 8 that when the drayage threshold is low (i.e. 100 miles), the truck uni-mode is generally preferred over intermodal. This is because the lower the threshold, the fewer opportunities there are for the intermodal option. In scenarios which have a higher number of new terminals, the railroad company has a better chance to increase its market share. The results indicate that when the drayage distance threshold ranges from 250 to 500, there is little difference in market share for intermodal and truck uni-mode. However, increasing the number of new terminals will increase the market share for the railroad company. It is also worth mentioning that different drayage distance thresholds affect the optimal location selection. As shown in Table 8, Greenville is the optimal terminal location when there is 1 new terminal and the drayage distance threshold is 100 miles, but Lexington becomes the optimal location when the drayage distance threshold is 250 and 350 miles. Thus, an important design consideration in determining the optimal locations is the shippers' drayage distance threshold. Such information could be easily obtained via survey and be incorporated into the model.

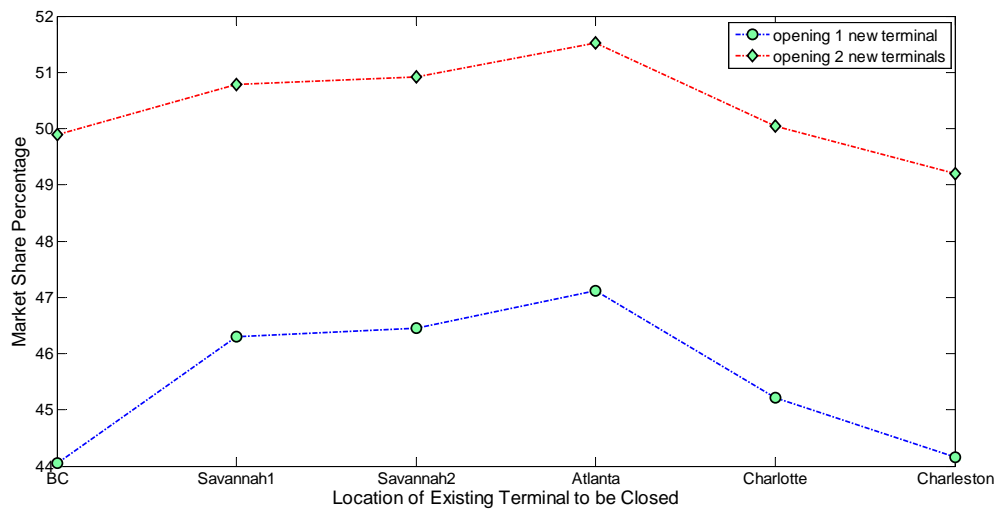

Fig. 5. Change in market share by closing one existing terminal and opening new terminals. 
Typically, a railroad company would expand its network by opening new terminals. Another option the manager may want to consider is closing an existing terminal which is not attracting enough demand and opening new terminals in more attractive locations. Such a situation was investigated. Two sets of experiments were conducted. The first involves closing one existing terminal and opening one new terminal, and the second one involves closing one existing terminal and opening two new terminals. The base case (BC) scenario for the first set of experiments involves closing no existing terminal and opening no new terminal, and the $\mathrm{BC}$ for the second set of experiments involves closing no existing terminal and opening one new terminal. The results shown in Fig. 5 indicate that by closing any of the existing terminals at the indicated locations (see x-axis labels) and opening 1 or 2 new terminals, the railroad company will gain market share compared to the base case. The only exception is Charleston. Note that the market share when closing the Charleston terminal is $49.2 \%$ compared to $49.9 \%$ of the BC. Closing the terminal located in Atlanta has the highest impact on market share for both cases (opening 1 or 2 new terminals). This result suggests that Atlanta terminal is the least attractive terminal among the existing terminals. It should be noted that the greatest increase in the total market share is about 3\% (scenario involving closing the Atlanta terminal and opening one new terminal). Thus, the manager will need to conduct a benefit-cost analysis to determine whether it is beneficial to close an existing terminal and open a new one.

\section{Conclusions}

This paper developed a mixed integer nonlinear programming model to find the best locations for new intermodal terminals and their capacities in a competitive environment with uncertain demand. Robust optimization models with min-max regret and minimum expected regret criteria were used to find solutions which are near optimal for any realization of demand scenarios. A simulated annealing algorithm was developed to solve the developed models. Computational experiments showed that the developed SA algorithm was able to find solutions with $0 \%$ gap compared to GAMS solutions, but in much shorter time for midsize problems. Moreover, the developed SA algorithm was able to solve larger-sized problems that GAMS could not (on a computer with 8 GB of RAM). The results verified that location and capacity decision is more robust when considering different scenarios of freight demands.

This work contributed to the literature of intermodal terminal location problem by considering competition between existing terminals and new terminals, terminal capacity, and uncertainty in freight demands. In future work, there are several potential areas for improvement. In the area of competition, it could be enhanced by considering utility functions based on transportation rates and dynamic travel times. In the area of terminal capacity, it could be enhanced by considering capacity expansion for existing terminals based on predicted freight demands. Lastly, it could be enhanced by utilizing fuzzy or stochastic approaches to deal with uncertainty in freight demands.

While the proposed model and solution approach have been validated via case studies, key limitations should be considered when reviewing study results. These included: 1) choice of network topology and size, 2) accuracy of FAF3 predicted freight flows, 3) design of the scenarios and experiments, and 4) objective of the optimization model that considers only profit from the new terminals.

\section{References}

Arnold, P., Dominique, P., \& Isabelle, T. (2004) .Modeling a rail/road intermodal transportation system. Transportation Research Part E, 40, 255-270.

Arostegui, M.A., Kadipasaoglu, S.N., \& Khumawala, B.M. (2006). An empirical comparison of Tabu search simulated annealing, and genetic algorithms for facilities location problems. International Journal of Production Economics, 103(2), 742-754. 
Ashtiani, M.G, Makui, A., \& Ramezanian, R. (2013). A robust model for a leader-follower competitive facility location problem in a discrete space. Applied Mathematical Modeling, 37(1), 62-71.

Ballis, A., \& Golias, J. (2004). Towards the improvement of a combined transport chain performance. European Journal of Operational Research,152, 420-436.

Bassan, S.H. (2007). Evaluating seaport operation and capacity analysis preliminary methodology. Maritime Policy \& Management: The flagship journal of international shipping and port research, 34(1), 3-19.

Battelle. FAF3 Freight Traffic Analysis. Freight Analysis Framework Version 3 (FAF3). Oak Ridge National Laboratory. FHWA, U.S. Department of Transportation, 2011.

Bookbinder, J.H., \& Fox N.S. (1998). Intermodal routing of Canada-Mexico shipments under NAFTA. Transportation Research Part E: Logistics and Transportation Review, 34(4), 289-303.

Chiranjivi, S.B. (2008). Framework for Evaluation of System Impacts of Intermodal Terminals using Commodity Flow Data. Center for Virginia Transportation Studies at the University of Virginia.

Crainic, T.G. (1998). A Survey of Optimization Models for Long-Haul Freight Transportation', Publication CRT-98-67. Centre for Research on Transportation.

Cunningham V (2012) 'S Siting of Freight Facilities', http://www.fhwa.dot.gov/planning/freight_planning/talking_freight/july182012transcript.cfm.

Daskin, M.S, Hesse, M.S, \& Revelle, CH.S. (1997). $\alpha$-reliable P-Minimax regret: A new model for strategic facility location planning. Location science, 5(4), 227-246.

Drezner, Z. (1995). Facility location-a survey of applications and methods. Berlin: Springer.

Drezner, T., Drezner, Z., \& Salhi, S. (2002). Solving the multiple competitive facilities location problem. European Journal of Operational Research, 142, 138-151.

Eiselt, H.A, \& Marianov, V. (2009). A conditional $p$-hub location problem with attraction functions. Journal of Computers \& Operations Research, 6, 3128 - 3135.

Ernst, A.T., \& Krishnamoorthy, M. (1999). Solution algorithms for the capacitated single allocation hub location problem. Annals of Operations Research, 86, 141-159.

Fotuhi, F., \& Huynh, N. (2013). A new planning model to support logistics service providers in selecting mode, route, and terminal location. Polish Maritime Research, 20, 67-73.

Gelareh, S., Nickel, S., \& Pisinger, D. (2010). Liner shipping hub network design in a competitive environment. Transportation Research Part E, 46, 991-1004.

Groothedde, B., Ruijgrok, C., \& Tavasszy, L. (2005). Towards collaborative, intermodal hub networks, A case study in the fast moving consumer goods market. Transportation Research Part E, 41(6), 567-583.

Huang, J., \& Wang, Q. (2009). Robust optimization of hub and spoke airline network design based on multi-objective genetic algorithm. Journal of Transportation Systems Engineering \& IT, 9(3), 86-92.

Huff, D.L. (1964). Defining and estimating a trading area. Journal of Marketing, 8, 28-34.

Ishfaq, R., \& Sox, C.R. (2010). Intermodal logistics: The interplay of financial, operational and service issues. Transportation Research Part E, 46(6), 926-949.

Ishfaq, R., \& Sox, C.R. (2011). Hub location-allocation in intermodal logistic networks. European Journal of Operational Research, 210(2), 213-230.

Johnson, D.S, Aragon, C.R, Mcgeoch, L.A., \& Schevon, C. (1989). Optimization by Simulated Annealing: an experimental evaluation; Part 1, Graph Partitioning. Operations Research, 37(6), 865892.

Kirkpatrick, S., Gelatt, C.D., \& Vecchi, M.P (1983). Optimization By simulated annealing. Science, 220, 671-680.

Kouvelis, P., \& Yu, G. (1997). Robust discrete optimization and its applications. Kluwer, Dordrecht.

Krumke, S.O. (2004). Nonlinear optimization. Technische Universität Kaiserslautern.

Limbourg, S., \& Jourquin, B. (2009). Optimal rail-road container terminal locations on the European network. Transportation Research Part E, 45(4), 551-563.

Lüer-Villagra, A., \& Marianov, V. (2013). A competitive hub location and pricing problem. European Journal of Operational Research, 231(3), 734-744. 
Makui, A., Rostami, M., Jahani, E.,\& Nikui, A. (2012). A multi-objective robust optimization model for the capacitated P-hub location problem under uncertainty. Management Science Letters, 2, 525534.

Marianov,V., Serra, D., \& Revelle, C. (1999). Location of hubs in a competitive environment. European Journal of Operational Research, 114(2), 363-371.

Meng, Q., \& Wang, X. (2011). Intermodal hub-and-spoke network design: Incorporating multiple stakeholders and multi-type containers. Journal of Transportation Research Part B, 45, 724-742.

Mulvey, J.M., Vanderbei, R.J., \& Zenios, S.A. (1995). Robust optimization of large-scale systems. Journal of Operations Research, 43(2), 264-281.

Murray, A.T., \& Church, R.L. (1996). Applying simulated annealing to location-planning models. Journal of Heuristics, 2, 31-53.

Nocera, S. (2009). A heuristic solution for the yearly capacity of an intermodal terminal. Journal of Interdisciplinary Mathematics, 12(3), 367-393.

Racunica, I., \& Wynter, L. (2005). Optimal location of intermodal freight hubs. Transportation Research Part B, 39, 453-477.

Rutten, B.J.C.M. (1995). On medium distance intermodal rail transport. Ph.D. thesis, Delft University of Technology, Delft.

Sahindis, N. (2013). Baron. Carnegie Mellon University, Department of Chemical Engineering. http://www.gams.com/dd/docs/solvers/baron.pdf.

Sirikijpanichkul, A., \& Ferreira, L. (2005). Multi-objective evaluation of intermodal freight terminal location decisions. In Proceedings of 27th Conference: Australian Institute of Transport Research.

Slack, B. (1990). Intermodal transportation in North America and the development of inland load centers. Professional Geographer, 42(1), 72-83.

Snyder, V.L., \& Daskin, M. (2005). Stochastic p-Robust Location Problems. IIE Transactions, 38 (11), 971-985.

Sorensen, K., Vanovermeire, CH., \& Busschaert, S. (2012). Efficient Meta heuristics to solve the intermodal terminal location problem. Computers \& Operations Research, 39(9), 2079-2090.

Tang, J., Tang, L., \& Wang, X. (2013). Solution method for the location planning problem of Logistics Park with variable capacity. Computers \& Operations Research, 40, 406-417.

Taniguchi, E., Noritake, M., \& Izumitani, T. (1999). Optimal size and location planning of public logistics terminals. Transportation Research Part E, 35, 207_222.

United Nations (Economic Commission for Europe), European Conference of Ministers of Transport (ECMT), and the European Commission (EC). Terminology on combined transport, New York and Geneva, 2001.

U.S. Department of Transportation Federal Railroad Administration. 2005. "Intermodal Transportation and Inventory Cost Model: Highway-to-Rail Intermodal (ITIC) User's Manual (computer software)".

Verter, V., \& Dincer, M.C. (1995). Facility Location and Capacity Acquisition: An Integrated Approach. Naval Research Logistics, 42, 1141-1 160. 